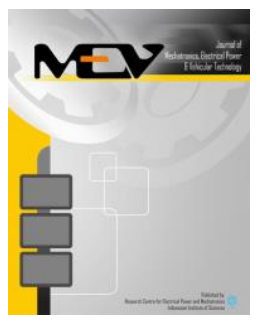

Journal of Mechatronics, Electrical Power, and Vehicular Technology

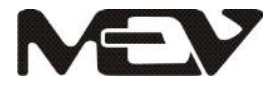

\title{
STUDY ON PERFORMANCE IMPROVEMENT AND ECONOMICAL aspect of Gas Turbine Power Plant Using EVAPORATIVE COOLING SYSTEM
}

\author{
Hilman Syaeful Alam ${ }^{\text {a, }}$, John Sasso ${ }^{\text {b }}$, Imam Djunaedi ${ }^{\mathrm{c}}$ \\ ${ }^{a}$ Technical Implementation Unit for Instrumentation Development, Indonesian Institute of Sciences \\ Jl. Sangkuriang Komplek LIPI Gedung 30 Bandung, 40135, Indonesia \\ ${ }^{b}$ RRT Sigma Engineering, One Huntington Quadrangle 3S-01 \\ Melville, New York, 11747, USA \\ ${ }^{c}$ Research Center for Physics, Indonesian Institute of Sciences \\ Jl. Sangkuriang Komplek LIPI Gedung 80 Lantai 2 Bandung, 40135, Indonesia
}

Received 5 May 2015; received in revised form 26 August 2015; accepted 17 September 2015 Published online 30 December 2015

\begin{abstract}
The study is intended to improve the performance of gas turbine engines in order to meet both electrical power demand and peak load in the power plant. In this paper, evaporative cooling system had been applied to improve the performance of gas turbine in Pesanggaran power plant in southern Bali Island, Indonesia. Moreover, the economic analysis was conducted to determine the capacity cost, operating cost and payback period due to the investment cost of the system. Based on the evaluation results, the power improvement for the three gas turbine units (GT1, GT2 and GT3) are $2.09 \%, 1.38 \%$, and $1.28 \%$, respectively. These results were not very significant when compared to the previous studies as well as on the aspects of SFC (Specific Fuel Consumption), heat rate and thermal efficiency. Based on the evaluation of the economic aspects, the reduction of production costs due to the application of evaporative cooling system was not economical, because it could not compensate the investment cost of the system and it resulted a very long payback period. These unsatisfactory results could be caused by the high relative humidity. Therefore, further studies are needed to investigate the other alternative technologies which are more suitable to the climate conditions in Indonesia.
\end{abstract}

Keywords: performance improvement; economic analysis; evaporative cooling; gas turbine; power plant.

\section{INTRODUCTION}

Gas turbines are the constant volume machines which always move the same volume of air at the given shaft speed. Since the combusted air is taken directly from the environment, their performance is strongly affected by ambient temperature. The power output of a gas turbine depends on the flow of mass through it. In hot days when air is less dense, power output falls off. A rise of $1{ }^{\circ} \mathrm{C}$ temperature of inlet air decreases the power output by $1 \%$ [1]. The simplest way to overcome the problem is to decrease the temperature of the inlet air. Inlet air cooling is considered the most effective technique to increase the power output

*Corresponding Author. Tel: +62-22-2503053

E-mail: alam_hilman@yahoo.com as well as thermal efficiency of industrial gas turbines. In general, the inlet air cooling technology on the gas turbine system can be classified into three types: evaporative cooling, chiling and fogging. Evaporative cooling is the most widely used method for power augmentation of gas turbine because it remains a most costs-efficient method for temperature control of the gas turbine inlet air supply [2].

Several studies have been done related to the issue of power augmentation, for simple cycle and combined cycle gas turbine using evaporative cooling technique [2-9]. Hamdan et al. [2] conducted a study on the performance improvement of a simple cycle gas turbine with a nominal rating of $250 \mathrm{MW}$. This engine is operated at Shuaiba Power Plant in Kuwait. The obtained results shows that the system appears to 
be capable of boosting generated power for about $11.07 \%$. Santos et al. [3] did the same study but applied to non-commercial gas turbine in Brazilian sites with increased power reached 9.65\%. Hosseini et al. [4] resulted in an increased output power of up to $13.3 \%$ which was applied to the combined cycle gas turbine power plant in Fars, Iran.

In this study, performance improvement of a simple cycle gas turbine using evaporative cooling system will be analyzed according to the different climatic conditions with previous studies. The case study was conducted in Pesanggaran power plant which owned and operated by Indonesia Power. This power plant is located in southern Bali Island, Indonesia, the load peaks occur during the early and late evening when the tourist hotels demand the most electricity. Moreover, the economic analysis was conducted to determine the capacity cost, operating cost and payback period due to the investment cost of the evaporative cooling system on the gas turbine.

\section{MATERIALS AND METHODS}

\section{A. Basic of Gas Turbine Cycle}

The basic of gas turbine operating cycle which also called Brayton cycle is depicted in Figure 1. It consists of a compression stage, a heat addition (combustion) stage and an expansion stage (turbine).

According to Santos et al. [3] and Oyedepo et al. [5], the following is the thermodynamic calculation for an open simple gas turbine cycle. In the existing condition or without a cooling system, the compressor inlet temperature is equal to ambient temperature, thus the inlet pressure is given by

$$
P_{0}=P_{03}
$$

where $P_{0}$ is inlet pressure, and $P_{03}$ is ambient pressure.

The air and combustion products are assumed as ideal gases. The pressure of the air leaving the compressor $\left(P_{04}\right)$ is calculated as:

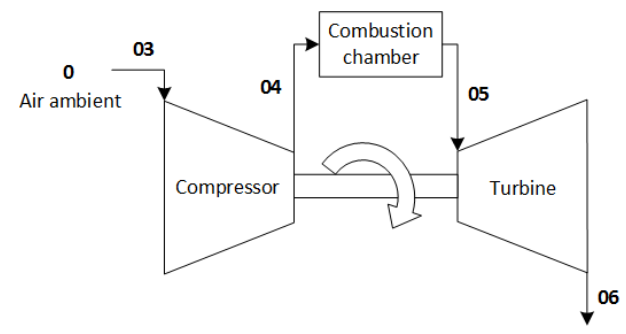

Figure 1. Schematic of the standard gas turbine cycle

$$
P_{04}=r P_{03}
$$

where $r$ is the compression ratio.

Assuming an ideal gas for state 04, the total temperature of the fluid leaving the compressor $\left(T_{04}\right)$ can be evaluated using ideal gas relations:

$$
T_{04}=\frac{T_{03}}{\eta_{c}}\left[\left(\frac{P_{04}}{P_{03}}\right)^{\frac{\gamma-1}{\gamma}}-1\right]+T_{03}
$$

where $T_{03}$ is ambient temperature, $\eta_{c}$ is the compressor efficiency and $\gamma$ is the specific heat ratio.

The compressor work $\left(\dot{W}_{C}\right)$ is calculated from the mass flow rate and enthalpy change across the compressor as follows:

$$
\dot{W}_{C}=\dot{m}_{a} C_{p a}\left(T_{04}-T_{03}\right)
$$

where $\dot{m}_{a}$ is the air-mass flow rate and $C_{p a}$ is the specific heat capacity of air at constant pressure.

The turbine inlet pressure $\left(P_{05}\right)$ can be calculated as:

$$
P_{05}=P_{04}\left(1-\Delta P_{c c}\right)
$$

where $P_{05}$ is the turbine entry level pressure, $P_{04}$ is the combustion chamber inlet pressure, and $\Delta P_{c c}$ is pressure drop across the combustion chamber.

The heat delivered by the combustion chamber $\left(\dot{Q}_{\text {in }}\right)$ is determined from energy balance:

$$
\dot{Q}_{\text {in }}=C_{p g}\left(T_{05}-T_{04}\right)
$$

where $C_{p g}$ is the specific heat capacity of combustion products and $T_{05}$ is the turbine inlet temperature.

By knowing lower heating value ( $L H V)$ of the fuel gas, the mass flow rate of fuel $\left(\dot{m}_{f}\right)$ is computed as:

$$
\dot{m}_{f}=\frac{\dot{Q}_{\text {in }}}{L H V \eta_{\text {com }}}
$$

where $\eta_{\text {com }}$ is combustor efficiency.

The exhaust temperature of the gas that leaves the turbine $\left(T_{06}\right)$ can be written as:

$$
T_{06}=T_{05}\left\{1-\eta_{T}\left[1-\left(\left(\frac{P_{05}}{P_{06}}\right)^{\frac{1-\gamma g}{\gamma g}}\right)\right]\right\}
$$

where $\eta_{T}$ is the turbine isentropic efficiency and $P_{06}$ is the ambient pressure.

Hence, the turbine power $\left(\dot{W}_{T}\right)$ is equal to:

$$
\dot{W}_{T}=\dot{m}_{g} c_{p g}\left(T_{05}-T_{06}\right)
$$

where $\dot{m}_{g}$ is the total mass flow rate of flue gas. It is composed of fuel and air mass flow rate $\left(\dot{m}_{g}\right)$ and given by

$$
\dot{m}_{g}=\dot{m}_{a}+\dot{m}_{f}
$$


The net power obtained from the gas turbine $\left(\dot{W}_{\text {Net }}\right)$ is given by:

$$
\dot{W}_{\text {Net }}=\dot{W}_{T}-\dot{W}_{c}
$$

The specific fuel consumption (SFC) compares the ratio of the fuel used by an engine to a characteristic power such as the amount of power produced by the engine [5]. SFC is determined by equation:

$$
S F C=\frac{3600 \dot{m}_{f}}{\dot{W}_{N e t}}
$$

Another important gas turbine parameter is the heat rate (HR) of a gas turbine cycle determined by:

$$
H R=S F C \times L H V
$$

Therefore, the thermal efficiency of the gas turbine $\left(\eta_{t h}\right)$ is calculated as:

$$
\eta_{t h}=\frac{\dot{W}_{N e t}}{\dot{m}_{f} L H V}
$$

\section{B. Evaporative Cooling System}

Figure 2 shows a schematic diagram of a gas turbine cycle with evaporative cooling system that is placed in the inlet compressor. Evaporative cooling is a passive process which

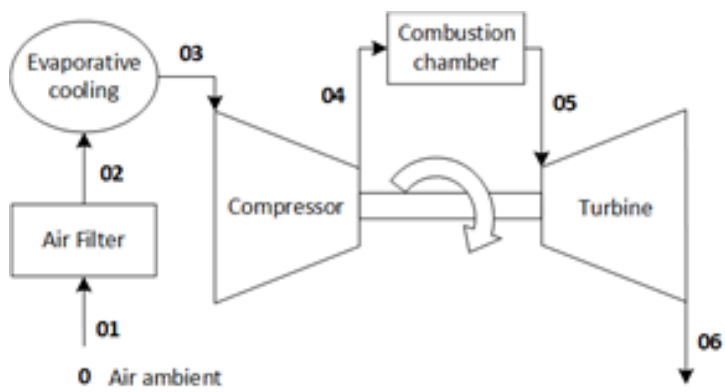

Figure 2. Schematic diagram of the gas turbine cycle with cooling system

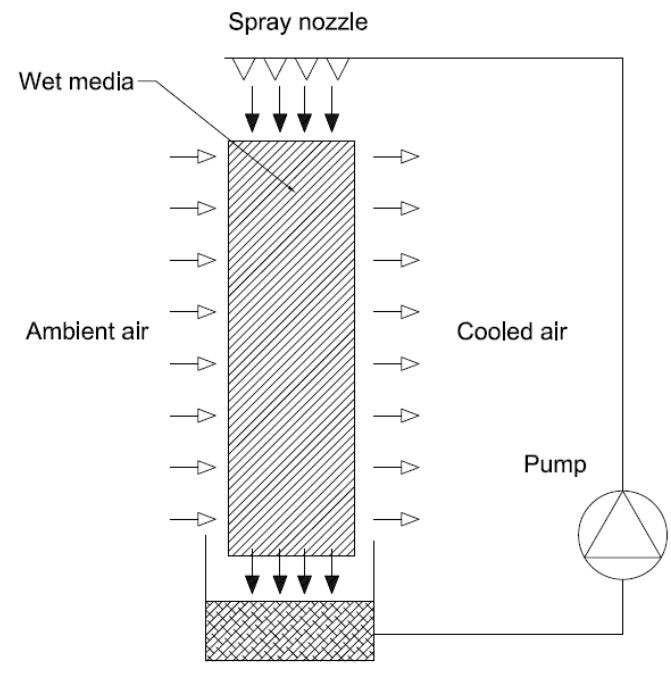

Figure 3. Schematic diagram of evaporative cooler the schematic can be seen in Figure 3. In the evaporative cooling system, a wet media is installed in the cross-section of the gas turbine filter house. The media is kept wet using high quality water, such as that from a reverse osmosis unit. The air entering the filter house passes over the saturated media, and the water contained in the media evaporates into the air stream on its way to the gas turbine [10].

The extent of the evaporation and the decreased of temperature is inversely proportional to the percentage of a humidity in the air stream [5], as shown in the saturation process in the psychrometric chart in Figure 4.

According to Santos et al. [3], the inlet air temperature after the cooling process $\left(T_{03}\right)$ in Figure 2 can be calculated as:

$$
T_{03}=T b_{02}-\varepsilon\left(T b_{02}-T w_{02}\right)
$$

where $T b_{02}$ is the dry-bulb temperature, $T w_{02}$ is the wet-bulb temperature and $\varepsilon$ is the cooling effectiveness.

The evaporated water mass flow associated with the evaporative cooling $\left(\dot{m}_{w}\right)$ is given by:

$$
\dot{m}_{w}=\dot{m}_{a}\left(\omega_{02}-\omega_{03}\right)
$$

where $\dot{m}_{a}$ is the air mass flow rate and $\omega_{02}$ and $\omega_{03}$ is the specific humidity in the inlet and outlet of the evaporative system respectively.

The cooling load due to evaporative cooling system $\left(\dot{Q}_{C L}\right)$ can be calculated by [5]:

$$
\dot{Q}_{C L}=\dot{m}_{a} C_{p a, a v g}\left(T_{02}-T_{03}\right)
$$

where $C_{p a, a v g}$ is the specific heat of dry air at constant pressure, determined as a function of the average temperature across the evaporative system.

\section{Existing Performance Data}

Table 1 summarizes the three gas turbines, manufacturer, years of commissioning and design capacity that are located at the Pesanggaran site. The existing performance of the three gas turbines is based on the latest plant performance test results which are shown in Table 2.

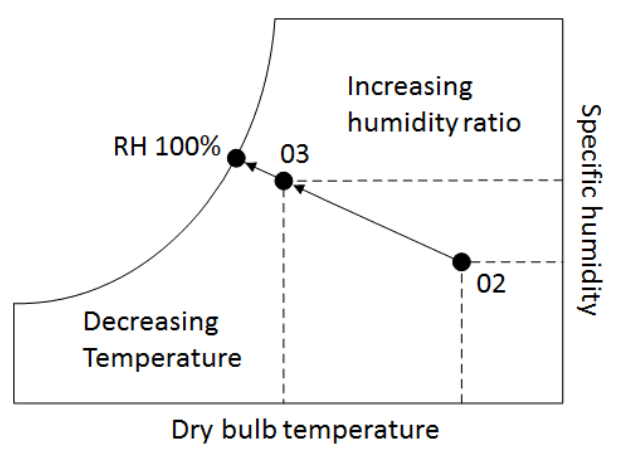

Figure 4. Saturation process in the psychrometric chart 
Table 1.

Pesanggaran gas turbine installation summary

\begin{tabular}{llllll}
\hline GT & OEM & Model & Yr & Cap. $[\mathbf{M W}]$ & $\mathbf{T}_{\text {amb }}\left({ }^{\mathbf{0}} \mathbf{C}\right)$ \\
\hline 1 & GE & MS-500-L & 1993 & $20.10(\mathrm{~B}) 23.05(\mathrm{P})$ & 30 \\
\hline 2 & Siemens & CW-251-B11 & 1994 & 42.07 & 27 \\
\hline 3 & Siemens & CW-251-B11 & 1994 & 42.07 & 27 \\
\hline
\end{tabular}

Table 2.

Gas turbine performance summary

\begin{tabular}{lllll}
\hline GT & Last capacity test date & Test results $(\mathbf{M W})$ & Aux. loads $(\mathbf{k W})$ & Tamb $\left({ }^{\circ} \mathbf{C}\right)$ \\
\hline 1 & $15 / 01 / 14(7 \mathrm{pm}-8 \mathrm{pm})$ & 16.30 & 220 & 30 \\
\hline 2 & $06 / 01 / 14(7 \mathrm{pm}-8 \mathrm{pm})$ & 39.80 & 161 & 30 \\
\hline 3 & $19 / 01 / 14(7 \mathrm{pm}-8 \mathrm{pm})$ & 35.40 & 98 & 30 \\
\hline
\end{tabular}

\section{Evaluation Methodology}

GTPro, a power cycle thermodynamic computer modeling software, was utilized to conduct the performance evaluation of the addition of evaporative cooling system on the three unit of gas turbine in Pesanggaran site.

The first step of evaluation is to replicate the New and Clean $(\mathrm{N} \& \mathrm{C})$ performance of each gas turbine at the design ambient conditions when the unit was installed. Site specific conditions are entered such as generator voltage, line voltage, site specific fuel composition, GT starter mechanism, and others. Using GTPro, the model is run at the ambient conditions of the latest performance test provided by the plant. Degradation factor can be calculated by comparing the corrected performance divided by the N\&C performance. Each GT is then modelled in GTPro with each of the performance improvements under consideration. The analysis is focused on power output, fuel consumption, heat rate, and thermal efficiency.

An estimation of the cost to install the gas turbine in current year dollars is determined using the GTPro capital cost estimating segment of the computer program (PEACE). It is assumed to use the default cost multipliers for Indonesia provided in GTPro for commodities, equipment, labor and materials which can be seen in Table 3 . The evaluation was focused to determine the capacity cost, operating cost and payback period due to the investment cost of the evaporative cooling system on the gas turbine.

Table 3.

Cost factors GTPro recommended for Indonesia

\begin{tabular}{lc}
\hline Category & Factor for Indonesia \\
\hline Specialized Equipment & 1.05 \\
\hline Other Equipment & 0.75 \\
\hline Commodities & 0.65 \\
\hline Labor & 0.54 \\
\hline
\end{tabular}

\section{RESULTS \& DISCUSSIONS}

Based on the evaluation methodology, the performance of gas turbine (GT) was analyzed using GTPro simulation. The initial step in the simulation is to analyze the effect of operating hours to the performance of New and Clean $(\mathrm{N} \& \mathrm{C})$ condition, therefore the results of evaluation before and after the addition of evaporative cooling system can be corrected by the degradation factor.

The simulation results for the N\&C performance of GT unit 2 (GT2) can be seen in Figure 5, while the result for the latest performance test can be seen in Figure 6. Based on these results, the degradation factor for the GT2 can be estimated at $2.4 \%$, the value is derived from the net amount of power based on the performance test divided by net power based on the N\&C performance. Degradation factors then are taken into account in the analysis of base and new performance by adding evaporative cooling system.

The simulation results of the base performance with degradation factor for GT2 can be seen in Figure 7, while the simulation results of new performance for GT2 by entering the degradation factor and cooling system is shown in Figure 8. Evaporative cooling process is designed with an increase in relative humidity approaching $100 \%$ saturation point where the ambient air conditions that were used as a reference in the analysis is the condition at the latest of the performance test. The ambient conditions in GT2 due to cooling process can be shown in the psychrometric chart in Figure 9. The ambient conditions before cooling are pressure at 14.69 psia, temperature at $80.6^{\circ} \mathrm{F}$ and relative humidity (RH) at $83 \%$. After passing through the evaporative cooling system, an increase in relative humidity reaches $98.04 \%$, which resulted in a decrease in temperature at the 
compressor inlet into $76.61^{\circ} \mathrm{F}$ (dropped $4.95 \%$ ) and pressure at 14.51 psia (dropped 1.23\%). A decrease in temperature at the compressor inlet impact on the performance improvement of the gas turbine.

Summary performance improvement of gas turbine in Pesanggaran power plant for unit 1 (GT1), unit 2 (GT2), and unit 3 (GT3) can be seen in Table 4, whereas the comparison between new three GT performance against the base performance can be seen in Figure 10. An increased power in the gas turbine as a result of the addition of evaporative cooling system can be referred to the additional net power which is calculated from the new power reduced by base power and parasitic load. Parasitic load is the extra power needed to run the cooling system that reduces the net power output of the gas turbine. Based on simulation results, the power improvement for the three gas turbine units (GT1, GT2, and GT3) respectively are $2.09 \%, 1.38 \%$, and $1.28 \%$. Based on the aspect of fuel consumption per power generated (SFC), there has been a decrease in incremental of SFC for

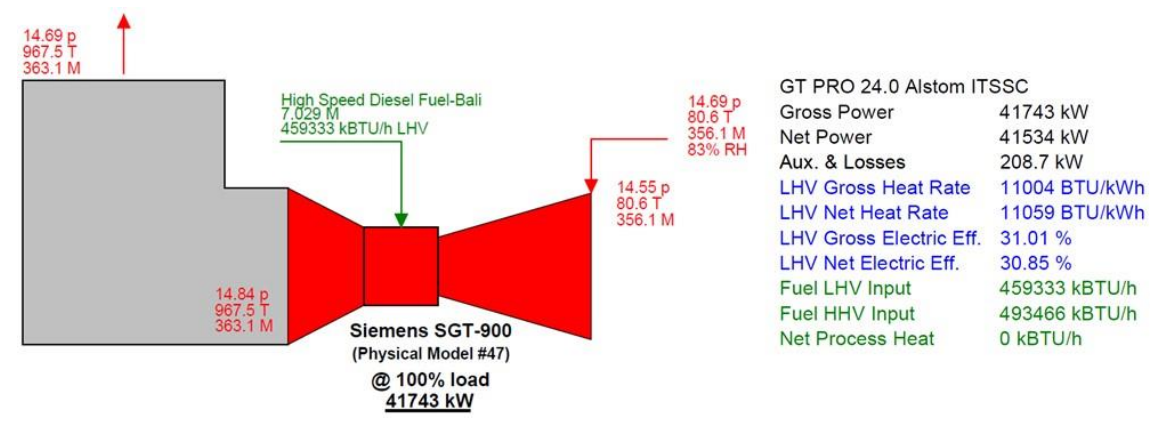

Figure 5. The simulation results of GT 2 for New \& Clean performance

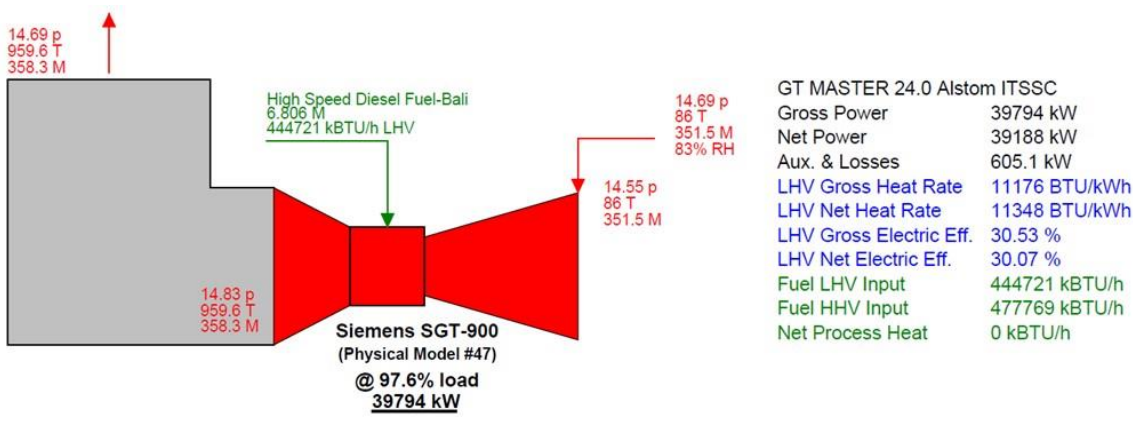

Figure 6. The simulation results of GT 2 for the latest performance test

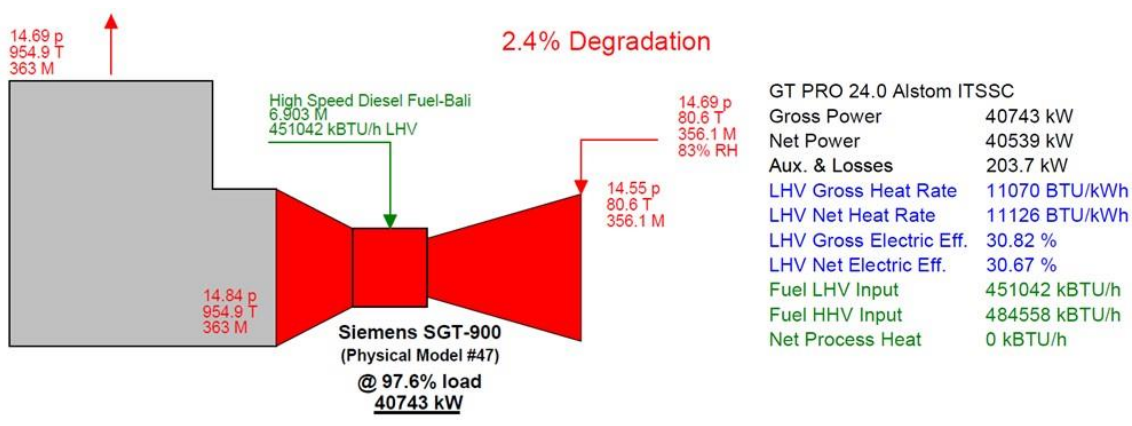

Figure 7. The simulation results of GT 2 for the base performance with degradation factor

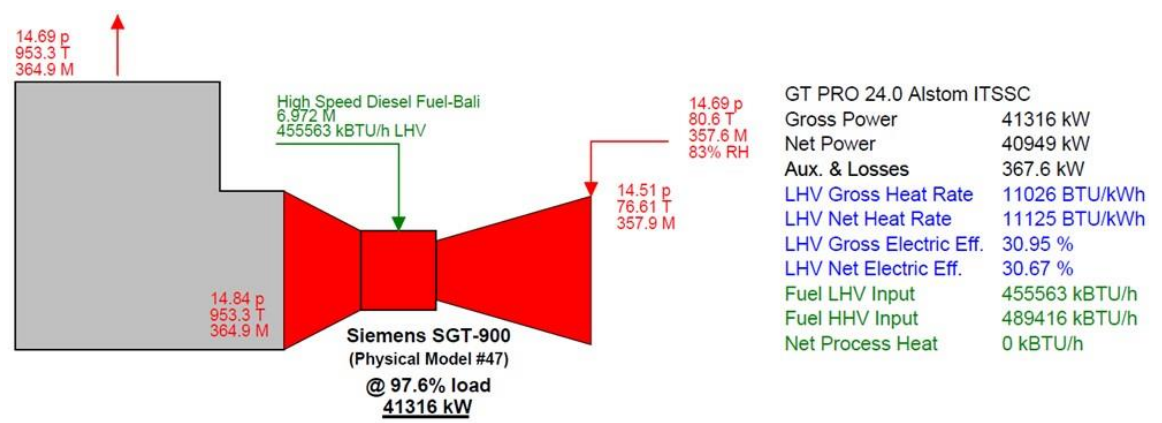

Figure 8. Simulation result of new GT performance with degradation factor and evaporative cooling 
GT1 and GT 3 for about $0.93 \%$ and $0.40 \%$, so the fuel consumption is lower than existing conditions respectively.

However on GT2, incremental of SFC against existing conditions is increased up to $0.20 \%$, this is because the degradation factor on GT 2 is $2.4 \%$ which is smaller than GT1 and GT3 that has the same degradation factor of $13.2 \%$. Therefore the application of evaporative cooling system on GT2 which has a performance similar to the $\mathrm{N} \& \mathrm{C}$ conditions is considered not economical to be applied.

This applies also to the value of incremental heat rate which is equal to the incremental SFC as a function of the same parameters. The incremental value for GT1, GT2, and GT3 respectively are $-0.93 \%, 0.20 \%$, and $-0.40 \%$. Based on the aspects of thermal efficiency, the improvement occurred in GT1 and GT3 with the efficiency improvement from the existing condition respectively are $0.23 \%$ and $0.12 \%$, while in GT2 the decrease in thermal efficiency is $0.06 \%$. The addition of evaporative cooling system on gas turbine has an impact on the additional cost, i.e. the investment or capacity cost. The calculation results of capacity cost using PEACE due to the addition of evaporative cooling system can be shown in Table 5. The investment costs are estimated based on the costs required for new plant with the addition of cooling system and the demineralized water plant reduced by the cost of base plant. If divided by the additional energy generated from addition of evaporative cooling system, the incremental capacity cost for GT1, GT2 and GT3 are 1,358.0, $1,023.1$, and 1,244.1 USD/kWh, respectively.

The incremental cost of capacity should ideally be balanced with a decrease in production costs due to the addition evaporative cooling system, so the payback period of the investment can be estimated. Assuming the gas turbine operated for 2000 hours in a year and fuel costs

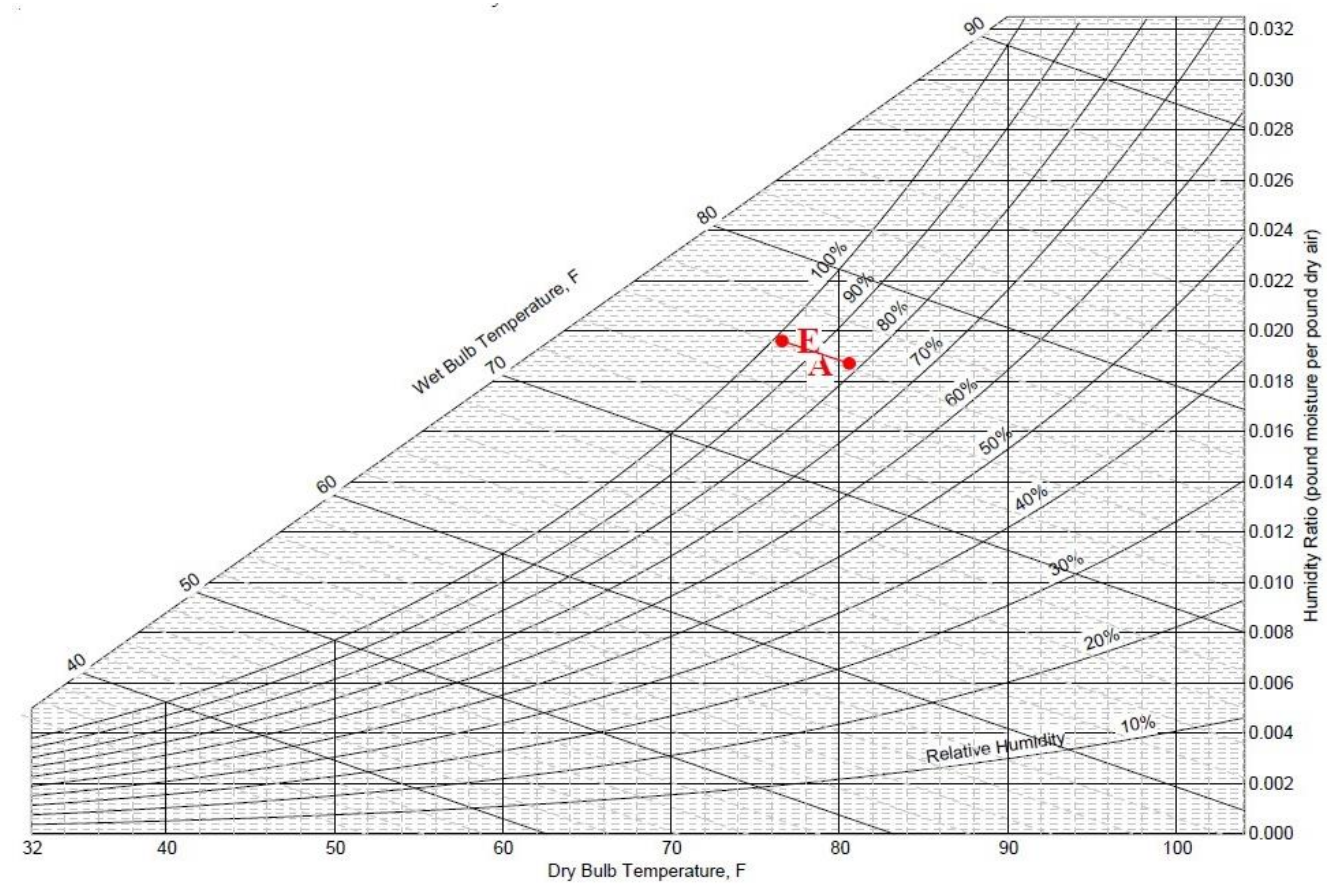

Figure 9. Psychrometric chart of GT inlet air after cooling process

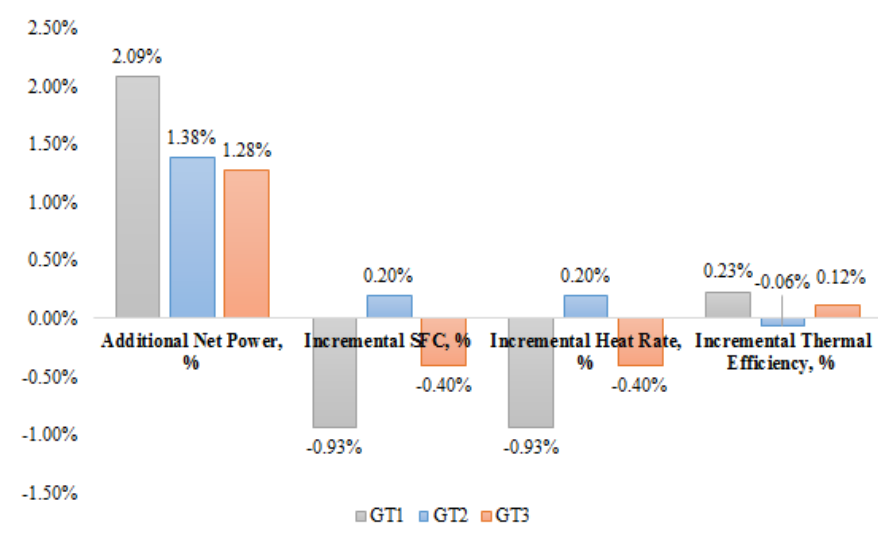

Figure 10. Performance comparison between three GT units after using evaporative cooling system against the base performance 
Table 4.

Performance of the three unit of gas turbine (GT) in Pesanggaran plant

\begin{tabular}{lrrr}
\hline Parameter & GT 1 & GT 2 & GT 3 \\
\hline Base power, kW & 16,203 & 40,743 & 36,249 \\
New power, kW & 16,548 & 41,316 & 36,722 \\
New parasitic load, kW & 7 & 10 & 10 \\
Additional net power, kW & 338 & 563 & 463 \\
Base heat rate, BTU/kWh & 13695.0 & 11004.0 & 11423.0 \\
New heat rate, BTU/kWh & 13567.0 & 11026.0 & 11377.0 \\
Incremental heat rate, BTU/kWh & -128.0 & 22.000 & -46.000 \\
Base specific fuel consumption, liter/kWh & 0.387 & 0.311 & 0.323 \\
New specific fuel consumption, liter/kWh & 0.383 & 0.311 & 0.321 \\
Incremental specific fuel consumption, liter/kWh & -0.00362 & 0.00062 & -0.00130 \\
Base thermal efficiency & $24.92 \%$ & $31.01 \%$ & $29.87 \%$ \\
New thermal efficiency & $25.15 \%$ & $30.95 \%$ & $29.99 \%$ \\
Incremental thermal efficiency & $0.23 \%$ & $-0.06 \%$ & $0.12 \%$ \\
\hline
\end{tabular}

Table 5.

Capacity cost evaluation results for the three unit of gas turbine (GT) in Pesanggaran plant

\begin{tabular}{lrrr}
\hline Parameter & GT 1 & GT 2 & GT 3 \\
\hline Additional net power due to cooling sytem, kW & 338 & 563 & 463 \\
\hline Cost base plant, kUSD & 22,232 & 33,379 & 33,379 \\
\hline Cost new plant, kUSD & 22,656 & 33,905 & 33,905 \\
\hline Cost Demin/RO plant, kUSD & 35 & 50 & 50 \\
\hline Estimated cost of cooling system, kUSD & 459 & 576 & 576 \\
\hline Capacity cost of cooling system, USD/kWh & $1,358.0$ & $1,023.1$ & $1,244.1$ \\
\hline
\end{tabular}

Table 6.

Operating cost evaluation results for the three unit of gas turbine (GT) in Pesanggaran plant for one year (2000 hr)

\begin{tabular}{lrrr}
\hline Parameter & GT 1 & GT 2 & GT 3 \\
\hline Base Electric Energy Generated, MWh & $32,406.0$ & $81,486.0$ & $72,498.0$ \\
\hline New Electric Energy Generated, MWh & $33,082.0$ & $82,612.0$ & $73,424.0$ \\
\hline Base Annual total fuel consumption, kilter & $12,535.9$ & $25,328.1$ & $23,392.5$ \\
\hline New Annual total fuel consumption, kilter & $12,677.8$ & $25,729.5$ & $23,595.8$ \\
\hline Base Annual Fuel Cost, kUSD & $11,031.6$ & $22,288.8$ & $20,585.4$ \\
\hline New Annual Fuel Cost, kUSD & $11,156.5$ & $22,641.9$ & $20,764.3$ \\
\hline Base Average power cost, USD/kWh & 0.3404 & 0.2735 & 0.2839 \\
\hline New Average power cost, USD/kWh & 0.3372 & 0.2741 & 0.2828 \\
\hline Incremental Average power cost, USD/kWh & -0.0032 & 0.0005 & -0.0011 \\
\hline
\end{tabular}

of $0.88 \mathrm{USD} /$ liter [11], the annual production cost can be shown in Table 6 . The ratio between the cost of fuel and energy produced can generate average power cost in one year. The difference in fuel consumption between the existing conditions (base) and after the application of cooling system (new) can be expressed as the incremental average power cost in USD/kWh per year. An average power cost reduction for GT1 and GT3 of one year respectively are $0.0032 \mathrm{USD} / \mathrm{kWh}$ and $0.0011 \mathrm{USD} / \mathrm{kWh}$, however for GT2 increases at $0.0005 \mathrm{USD} / \mathrm{kWh}$, so the evaporative cooling system on GT2 is not economical. If the decrease in annual production costs on the GT1 and GT3 is compared to the investment cost of the cooling system, the fastest payback period can reach until 544 years.

\section{CONCLUSION}

Performance of improvement analysis of gas turbine in Pesanggaran power plant due to the addition of the evaporative cooling system is focused on increasing power, specific fuel consumption (SFC), heat rate and thermal efficiency. Based on the evaluation results, the power improvement for the three gas turbine 
units (GT1, GT2, and GT3) respectively are $2.09 \%, 1.38 \%$, and $1.28 \%$. These results are not very significant compared to the previous studies with the enhancement of power ranges between $5-13.3 \%$. These apply also to the SFC, heat rate and thermal efficiency, where the influence of evaporative cooling system does not have a significant impact to the performance of the gas turbine. This could be caused by the high relative humidity in Pesanggaran site so that a decrease in turbine inlet temperature from the existing conditions is less effective only around $4.95 \%$, whereas in previous studies could reach between $30-35 \%$. Based on the evaluation of the economic aspects, capacity costs which are calculated from the investment cost of the evaporative cooling system and demineralized water plan for GT1, GT2 and GT3, respectively are 1,358.0, 1,023.1 and 1,244.1 USD/kWh. These capacity costs should be balanced with a decrease in the production cost. However the production costs reduction due to the evaporative cooling system application on the three units of gas turbine was not economical because it could not compensate the investment cost of the system and it resulted a very long payback period. Further studies are needed to investigate the other alternative technologies which are more suitable to the climate conditions in Indonesia.

\section{ACKNOWLEDGEMENT}

This research is motivated by a memorandum of understanding (MoU) which has been implemented by the Indonesian Institute of Sciences (LIPI) and PT. Indonesia Power in the fields of research and development of electricity on November 7, 2011 with the MoU Number: 8.MOU/2/IP/2011 and 10/KS/LIPI/IX/2011.

\section{REFERENCES}

[1] Thamir K. Ibrahim et al., "Improvement of gas turbine performance based on inlet air cooling systems: A technical review," International Journal of Physical Sciences, Vol. 6(4), 18 February, 2011, pp. 620-627.

[2] O. R. AL-Hamdan and A. A. Saker, "Studying the Role Played by Evaporative Cooler on the Performance of GE Gas Turbine Existed in Shuaiba North Electric Generator Power Plant, " Energy and Power Engineering, Vol. 5, 2013, pp. 391-400.
[3] A. P. Santos and C. R. Andrade, "Analysis of Gas Turbine Performance with Inlet Air Cooling Techniques Applied to Brazilian Sites," J. Aerospace. Technol. Manag., Vol.4, No 3, Jul.-Sep., 2012, pp. 341-353.

[4] R. Hosseini et al., "Performance improvement of gas turbines of Fars (Iran) combined cycle power plant by intake air cooling using a media evaporative cooler," Energy Conversion and Management, Vol. 48, 2007, pp. 1055-1064.

[5] S. O. Oyedepo and O. Kilanko, "Thermodynamic Analysis of a Gas Turbine Power Plant Modeled with an Evaporative Cooler," International Journal of Thermodynamics, Vol. 17, No. 1, 2014, pp. 14-20.

[6] S. Agarwal et al., "Performance Improvement of a Regenerative Gas Turbine Cycle Through Integrated Inlet Air Evaporative Cooling and Steam Injection," International Journal of Emerging Technology and Advanced Engineering, Vol. 2, Issue 12, December 2012, pp. 354-363.

[7] E. Farvaresh et al., "Investigation of Gas Turbine Intake Air Cooling via Evaporative Media and Its Effects on Cartridge Filters Pressures Drop," International Journal of Occupational Hygiene, Vol. 6, No. 2, 2014, pp. 75-80.

[8] A. D. Pascale et al., "Analysis of Inlet Air Cooling for IGCC Power Augmentation," Energy Procedia, Vol. 45, 2014, pp. 12651274.

[9] R. Espanani et al., "Efficiency Improvement Methods of Gas Turbine," Energy and Environmental Engineering, Vol. 1(2), 2013, pp. 36-54.

[10] Technical Report, Evaluation of Gas Turbine Performance Improvement Alternatives for Indonesia Power, Power Phase LLC and Indonesian Institute of Sciences, No. 1246-001-01, January 28, 2015.

[11] Indonesia Diesel prices, liter, available at: http://www.globalpetrolprices.com/Indonesi a/diesel_prices/. 